\title{
Determination of trace levels of Cd(II) in tap water samples by anodic stripping voltammetry with an electrografted boron-doped diamond electrode
}

\author{
Chalermpol Innuphat $^{\mathrm{a}, *}$, Pipat Chooto ${ }^{\mathrm{a}}$ \\ a Department of Chemistry, Analytical Chemistry Division, Faculty of Science, \\ Prince of Songkla University, Hatyai, Songkhla 90112 Thailand \\ *Corresponding author, e-mail: chalermpoli@hotmail.com
}

Received 28 Oct 2015

Accepted 12 Feb 2017

\begin{abstract}
A boron-doped diamond electrode modified by $0.5 \mathrm{mM}$ 4-aminomethyl benzoic acid was used for electrochemical determination of $\mathrm{Cd}^{2+}$ in tap water samples by anodic stripping voltammetry. This method is based on the electrochemical reduction of 4-aminomethyl benzoic acid on the electrode followed by the determination of $\mathrm{Cd}^{2+}$ with a single well-defined reduction peak at $-0.72 \mathrm{~V}$ versus $\mathrm{Ag} / \mathrm{AgCl}$ in acetate buffer solutions at $\mathrm{pH}$ 6.0. Optimal conditions were established with respect to electrode pretreatment, time accumulation, potential accumulation, scan rate, and $\mathrm{pH}$. Accurate $\left(r^{2}=0.9989, n=6\right)$ calibration curves were obtained for $\mathrm{Cd}^{2+}$ concentrations ranging between $2 \mathrm{ppb}$ and $50 \mathrm{ppb}$. Other dissolved metals (Ca, Mg, $\mathrm{Zn}, \mathrm{Mn}, \mathrm{Fe}, \mathrm{Cu}, \mathrm{Al}, \mathrm{Co}, \mathrm{Pb}$, and $\mathrm{Ni}$ ) have no interference on the $\mathrm{Cd}^{2+}$ calibration curves. The achieved detection limit was $0.2 \mathrm{ppb}$. High accuracy and reproducibility of the results as well as excellent stability of the electrode material proves superb capabilities of this $\mathrm{Cd}^{2+}$ detection system. Recovery in the range of $97-102 \%$ further confirmed the usefulness of the proposed method to analyse $\mathrm{Cd}^{2+}$ in tap water samples. The results with SRM1640 were in good agreement with those by inductively coupled plasma optical emission spectrometry.
\end{abstract}

KEYWORDS: voltammetric analysis, ASV, $\mathrm{Cd}^{2+}$

\section{INTRODUCTION}

The contamination of utility water with heavy metals such as $\mathrm{Cd}^{2+}$ is one of the most hazardous environmental and health problems. Those metals are highly toxic to certain organs of both humans and animals, including nervous, immune, reproductive, and gastrointestinal systems ${ }^{1}$. Ingestion of any significant amount of $\mathrm{Cd}^{2+}$ causes immediate poisoning as well as damage to the liver and the kidneys because of their tendency to accumulate in the body, toxicity, and low clearance rate. The biological half-life of $\mathrm{Cd}^{2+}$ is $10-30$ years ${ }^{2}$ and compounds containing $\mathrm{Cd}^{2+}$ are also carcinogenic ${ }^{3}$. Building up of $\mathrm{Cd}^{2+}$ levels in the water, air, and soil has been increasing, particularly in industrial areas. Workers can be exposed to $\mathrm{Cd}^{2+}$ in air from the smelting and refining of metals, or from the air in industrial plants that make $\mathrm{Cd}^{2+}$ products such as batteries, coatings, or plastics. Even cigarettes are a significant source of $\mathrm{Cd}^{2+}$ exposure. Although there is generally less $\mathrm{Cd}^{2+}$ in tobacco than in food, the lungs absorb $\mathrm{Cd}^{2+}$ more efficiently than the stomach ${ }^{4}$. Some sources of phosphate in fertilizers contain $\mathrm{Cd}^{2+}$ up to the amounts of $100 \mathrm{mg} / \mathrm{kg}^{5,6}$, which can lead to an increase in the concentration of $\mathrm{Cd}^{2+}$ in soil as found in New Zealand ${ }^{7}$. In addition, Nickel-cadmium batteries are one of the most popular and most common cadmium-based products. Environmental exposure to $\mathrm{Cd}^{2+}$ has been particularly problematic in Japan where many people have consumed rice that was grown in $\mathrm{Cd}^{2+}$ contaminated irrigation water. This phenomenon is known under the name itai-itai disease ${ }^{8}$. The determination of trace level $\mathrm{Cd}^{2+}$ in water samples therefore plays an important role in the environmental pollution monitoring due to the cumulative toxicity of $\mathrm{Cd}^{2+}$.

Sensitive methods to determine trace amount of $\mathrm{Cd}^{2+}$ have received much attention and many techniques have been developed. Typical methods of metal ion analysis include inductively coupled plasma-mass spectrometry ${ }^{9}$, X-ray fluorescence spectrometry (XRF) ${ }^{10}$, and atomic absorption spectrometry (AAS) ${ }^{11}$. However, these techniques use expensive and sophisticated instruments and are time consuming, which severely restricts their practical applications ${ }^{1}$. Anodic stripping voltammetry is a well established method for trace analysis of heavy metals. The equipment for ASV measurement is inexpensive because of its small size and does not 
demand a high power supply. This makes field deployment possible and constitutes a big advantage over AAS or ICP. Generally, the detection limit of ASV is not as low as the detection limit of the spectrometric measurements, but still adequate for most of the tasks mentioned above ${ }^{12}$. One of the extensively used electrode materials for ASV is mercury. Nowadays, however, mercury electrodes are considered undesirable due to the toxicity of both metallic mercury and mercury salts employed for its preparation. Alternative environmentally friendly electrode materials are therefore required ${ }^{13}$. Several new types of mercury-free electrodes have recently been developed for sensitive metal determinations, including bismuth film electrodes 13,14 , gold-coated electrodes $^{15,16}$, silver electrodes ${ }^{17,18}$, glassy carbon electrodes ${ }^{19}$, carbon paste electrodes ${ }^{20-22}$, carbon nanotube electrodes ${ }^{23}$, or screen-printed carbon electrodes ${ }^{24}$.

Boron-doped diamond (BDD) electrodes can be applied in a variety of areas due to their superior properties, including extreme robustness with a low level of background interference, less adsorption of polar molecules, and wide potential window in aqueous media ${ }^{2,25}$. It has been used to quantify manganese in tea ${ }^{26}$ as well as lead in tap water ${ }^{27}$ and river sediment. Anodic stripping voltammetry BDD has been proved to possess outstanding features ${ }^{28}$ to determine silver ${ }^{29}$ and simultaneous detection of lead and copper ${ }^{30}$.

This paper reports the detection of $\mathrm{Cd}^{2+}$ by ASV on BDD electrode based on simple and selective electrochemical reduction of $\mathrm{Cd}^{2+}$ on diazoniummodified electrode with interference study. The method was verified by analysing standard material and was then applied to the analysis of Cd in Hatyai tap water. The modification of carbon through the electrochemical or chemical reduction of aromatic diazonium derivatives has been extensively used for modification of various carbon materials, such as glassy carbon ${ }^{31}$, graphite ${ }^{32}$, graphene ${ }^{33}$, and carbon nanotube ${ }^{34}$. It is well-recognized as a very versatile and simple way to graft a wide variety of functional groups onto carbon surfaces for various applications. Furthermore, the diazonium-modified electrode has been found to be stable to long-term storage in air and organic solvents. The high stability of the diazonium-modified electrode and the versatility of the diazonium modification method are particularly attractive for stripping analysis. Due to these characteristics, the method can therefore be applied well to $\mathrm{Cd}^{2+}$ analysis.

\section{MATERIALS AND METHODS}

\section{Reagents and solutions}

All reagents were used as received without any further treatment. $\mathrm{Cd}^{2+}$ standards were prepared in-house from $\mathrm{Cd}^{2+}$ nitrate Atomic Spectroscopy Standard Solution. $\mathrm{KNO}_{3}$ as a supporting electrolyte was supplied by Ajax Finechem. All other reagents and the metal salts used for the interference experiments (all nitrates except $\mathrm{MnCl}_{2} \cdot 4 \mathrm{H}_{2} \mathrm{O}$ and $\mathrm{MgCl}_{2} \cdot 6 \mathrm{H}_{2} \mathrm{O}$ ) were of analytical-reagent grade with the highest purity commercially available. All subsequent solutions were prepared by using deionized water of resistivity not less than $18 \mathrm{M} \Omega \mathrm{cm}$ (ELGA water purification system, England). Nitrogen gas (99.99\%) was used to deaerate the testing solutions for $2 \mathrm{~min}$. Laboratory glassware was kept overnight in $10 \%(\mathrm{v} / \mathrm{v}) \mathrm{HNO}_{3}$ solution and rinsed with deionized water before use. Standard solutions of $\mathrm{Cd}^{2+}$ were prepared by diluting the respective stock solutions with high purity deionized water and stored in polyethylene bottles before use.

The reference sample analysed was NIST (National Institute of Standards and Technology) SRM 1640 trace elements in natural water. NIST SRM 1640 is composed of natural fresh water from Clear Creek, Colorado, USA. The sample was filtered and stabilized with $\mathrm{HNO}_{3}$ to a concentration of $0.5 \mathrm{M}$. The certified value of $\mathrm{Cd}^{2+}$ was $22.82 \pm 0.96 \mathrm{ppb}$.

\section{Sampling and digestion}

Tap water samples were collected between August and September 2015 in different regions within the city of Hatyai, Songkhla, Thailand. An aliquot of $500 \mathrm{ml}$ of tap water sample was digested by mixing with $2 \mathrm{ml}$ of concentrated $\mathrm{HNO}_{3}$ and $2 \mathrm{ml}$ of $\mathrm{KNO}_{3}$ and then placed in cleaned polyethylene bottles.

\section{Instrumentation}

Cyclic voltammetry (CV) and square wave anodic stripping voltammetry (SWASV) were performed with a Powerlab 2/20 with Potentiostat (ADInstrument, Australia) controlled by ECHEM. The threeelectrode system consisted of an $\mathrm{Ag} / \mathrm{AgCl} / 3 \mathrm{M} \mathrm{KCl}$ reference electrode, a platinum counter electrode, and a BDD electrode with inner diameter of $3 \mathrm{~mm}$ (Windsor Scientific Ltd., UK) was used as a working electrode. All electrochemical measurements were carried out in a $50 \mathrm{ml}$ cell and the $\mathrm{pH}$ of solutions were measured by $\mathrm{pH}$ meter Model 510 (Eutech instruments, USA). 


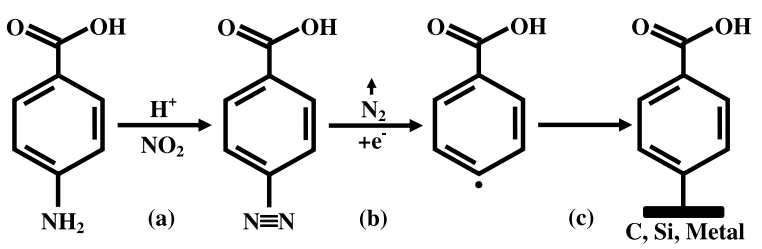

Fig. 1 Grafting process through the electrochemical reduction of diazonium salts. (a) Spontaneous diazotization, (b) electrochemical reduction, and (c) grafting on the electrode surface.

\section{Preparation of modified electrode}

The modification of thin films by electrofunctionalization was electrochemically performed by the reductive electrolysis of diazonium salts on the electrode surface. Diazonium salts were directly generated in the electrochemical cell by the spontaneous diazotization method using an aromatic amine presenting an adequate substituent in the para-position relative to the amino group $\left(-\mathrm{NH}_{2}\right)$. The in situ transformation of the amine into a diazonium salt $\left(-\mathrm{N}_{2}^{+}\right)$was carried out with an aqueous nitrite solution $(10 \mathrm{mM}$ tetrabutylammonium hexafluorophosphate, $\mathrm{TBAPF}_{6}$ ) in acidic medium $(\mathrm{HCl}$, $\mathrm{pH}=2$ ). Fig. 1 shows the electrochemical reduction of diazonium salts to immobilize organic layers on the electrodes surface. The electrochemical grafting was carried out under stirring (400 rpm) in a cyclic voltammetry mode ( 5 cycles) between 0.2 and $-1.2 \mathrm{~V}$ versus $\mathrm{Ag} / \mathrm{AgCl}$ at $100 \mathrm{mV} / \mathrm{s}$. The aqueous electrolyte was composed of $10 \mathrm{mM} \mathrm{TBAPF}_{6}, 0.5 \mathrm{M}$ $\mathrm{HCl}$ and $0.5 \mathrm{mM}$ 4-aminomethyl benzoic acid.

\section{$\mathrm{Cd}^{2+}$ determination procedure}

Stripping voltammetric measurements were performed with a BDD electrode and the target metal $\mathrm{Cd}^{2+}$ in the presence of dissolved oxygen. Prior to its use, the BDD electrode was polished with a $0.05 \mu \mathrm{m}$ alumina slurry. The three electrodes were immersed into a $50 \mathrm{ml}$ electrochemical cell containing $\mathrm{pH} 6.0$ acetate buffer solutions. A deposition potential of $-1.10 \mathrm{~V}$ for measurements of $\mathrm{Cd}^{2+}$ was applied to the BDD electrode in the stirred solution. Following a preconcentration step of $120 \mathrm{~s}$, the stirring was stopped; and after $30 \mathrm{~s}$, the voltammogram was recorded by sweeping the potential from -1.0 to $-0.3 \mathrm{~V}$ (with scan rate $10 \mathrm{mV} / \mathrm{s}$, a frequency of $10 \mathrm{~Hz}$, amplitude of $4 \mathrm{mV}$, and potential step of $25 \mathrm{mV}$ ). Aliquots of the $\mathrm{Cd}^{2+}$ standard solution were introduced after recording the background voltammograms. The peak currents were measured

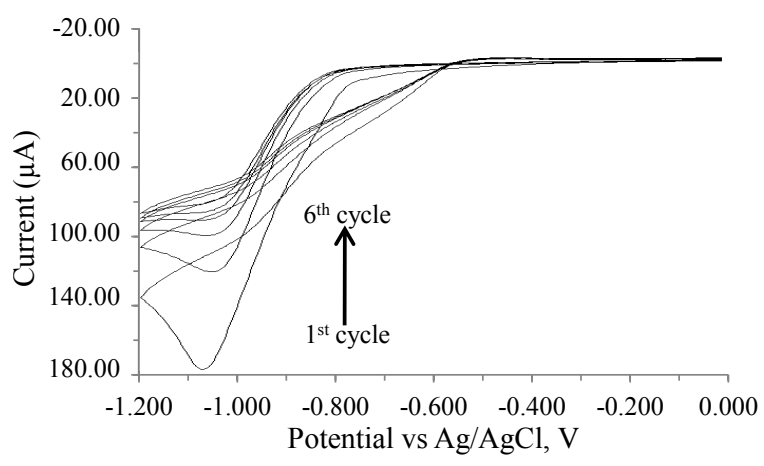

Fig. 2 Electrografting of BDD electrodes with $0.5 \mathrm{mM}$ 4-aminomethyl benzoic acid in methanol with $10 \mathrm{mM}$ TBAPF $_{6}$ as an electrolyte with the 1st, 2nd, 3rd, 4th, 5th, and 6 th potential $\mathrm{CV}$ cycles for scan rate $100 \mathrm{mV} / \mathrm{s}$.

at $-0.72 \mathrm{~V}$. A $30 \mathrm{~s}$ conditioning step at $+0.3 \mathrm{~V}$ (with stirred solution) was applied to fully oxidize all metal deposits prior to the next measurement. All experiments were carried out at room temperature.

\section{RESULTS AND DISCUSSION}

\section{Electrografting BDD electrode with 4-aminomethyl benzoic acid}

The reduction of diazonium salts was carried out in a narrow potential range between 0.2 and $-1.2 \mathrm{~V}$ (Fig. 2). The broad reduction peak present in the first cycle (at $-1.08 \mathrm{~V}$ ) is presumably attributed to the reduction of the corresponding diazonium species to form an aryl radical which reacts with the electrode surface. It can therefore be assumed that the same phenomenon occurred in the current study, namely, is the covering of BDD electrodes by the corresponding aryl layers.

\section{Evolution of the wettability}

To characterize the wettability of the electrolyte on the BDD modified electrode, the droplets of distilled water after grafting with 4-aminomethyl benzoic acid were found to induce an increase in the contact angle from $22^{\circ}$ to $68^{\circ}$ (figure not shown), indicating that the hydrophobicity is greater with the presence of the aromatic ring.

\section{Cyclic voltammogram of $\mathrm{Cd}^{2+}$}

The overlay of CV voltammograms for $30.0 \mathrm{mg} / \mathrm{l}$ $\mathrm{Cd}^{2+}$ in the absence (curve a) and presence (curve b) of electrografted BDD electrode is shown in Fig. 3. The deposition peak was observed at $-0.92 \mathrm{~V}$ versus $\mathrm{Ag} / \mathrm{AgCl}$ corresponding to preconcentration of $\mathrm{Cd}^{2+}$ onto a BDD electrode surface at negative 


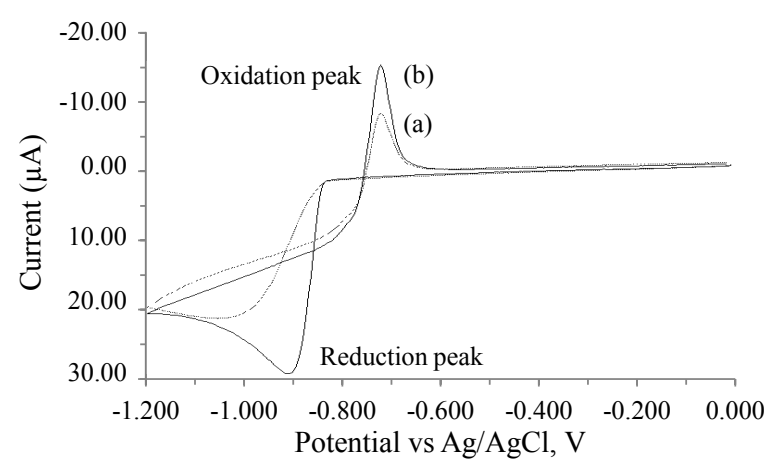

Fig. 3 Cyclic voltammogram of $30.0 \mathrm{mg} / \mathrm{l} \mathrm{Cd}^{2+}$ at (a, dashed line) bare BDD electrode and (b, solid line) the modified electrode in $\mathrm{pH} 6.0$ acetate buffer solutions with scan rate of $100 \mathrm{mV} / \mathrm{s}$.

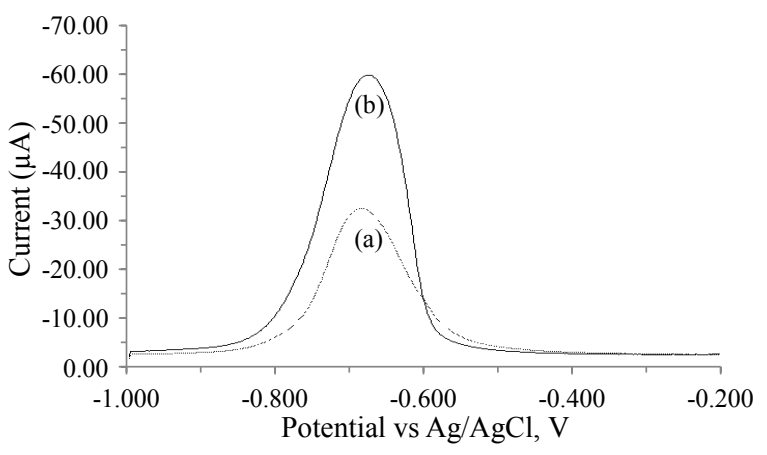

Fig. 4 SWASV of $\mathrm{Cd}^{2+}$ at (a, dashed line) bare BDD electrode and (b, solid line) the modified electrode. Experimental conditions: deposition/measurement solution, pH 6.0 acetate buffer solutions containing $30.0 \mathrm{mg} / 1$ $\mathrm{Cd}^{2+}$; deposition time, $120 \mathrm{~s}$, potential $1.0 \mathrm{~V}$, frequency $10 \mathrm{~Hz}$, amplitude of $4 \mathrm{mV}$, and potential step of $25 \mathrm{mV}$.

potentials. On the reverse scan, the single well defined stripping peak appeared at potential around $-0.72 \mathrm{~V}$ versus $\mathrm{Ag} / \mathrm{AgCl}$ with electrografted $\mathrm{BDD}$ electrode surface.

\section{The electrochemical response of $\mathrm{Cd}^{2+}$ stripping on bare and benzoic acid-modified BDD electrode}

Fig. 4 shows square wave anodic stripping voltammograms (SWASV) of $\mathrm{Cd}^{2+}$ at bare and benzoic acid-modified BDD electrode, both reflecting welldefined peak at $0.72 \mathrm{~V}$. The anodic peak current of $\mathrm{Cd}^{2+}$ at the benzoic acid-modified BDD electrode $(58.5 \mu \mathrm{A})$ was about twice of that at the bare BDD electrode $(32.0 \mu \mathrm{A})$. The increases in anodic peak current are attributed to the electrostatic interaction between the negatively charged electrografted BDD

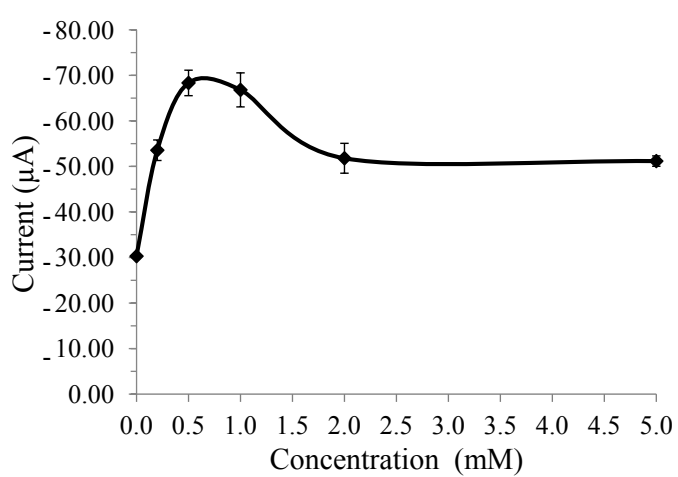

Fig. 5 Peak currents from BDD electrode at concentration of $30.0 \mathrm{mg} / 1 \mathrm{Cd}^{2+}$ with various concentrations of 4-aminomethyl benzoic acid 0.0, 0.2, 0.5, 1.0, 2.0, and $5.0 \mathrm{mM}$ in acetate buffer solutions $\mathrm{pH} 6.0$ with scan rate of $100 \mathrm{mV} / \mathrm{s}$.

electrode and the positively charged metal ions that facilitates the preconcentration of $\mathrm{Cd}^{2+}$ which are beneficial for $\mathrm{Cd}^{2+}$ determination.

\section{Effect of concentration of 4-aminomethyl benzoic acid}

The dependence of the peak $\mathrm{Cd}^{2+}$ currents on the concentration of 4-aminomethyl benzoic acid is depicted in Fig. 5. It is apparent that 4-aminomethyl benzoic acid film can increase peaks height of $\mathrm{Cd}^{2+}$ oxidation, a sharp increase in the response signal can be observed with increasing concentration of 4-aminomethyl benzoic acid from 0.0-0.5 mM followed by a decrease from $1.0-5.0 \mathrm{mM}$. When the concentration of 4-aminomethyl benzoic acid was very high, the formation of a thick layer probably partially blocked the conductive surface of the electrode, resulting in a decrease of electrodeposition sites. The optimum concentration with the highest current was $0.5 \mathrm{mM}$, which was selected for further experiments.

\section{Electrolyte and $\mathrm{pH}$ dependence for film formation}

Since the electrografting on electrode surfaces depends mainly on acidity, $\mathrm{pH}$ can be one of the effective parameters strongly influencing the peak current. The $\mathrm{pH}$ range of 1.0-8.0 (data not shown) was investigated using cyclic voltammetry in $10 \mathrm{mM}$ $\mathrm{TBAPF}_{6}$ as an electrolyte. With the increase of $\mathrm{pH}$ from 1.0-2.0, the peak current continuously increases due to greater extent of complex formation of $\mathrm{Cd}^{2+}$ with 4-aminomethyl benzoic acid at the electrode surface. However, with $\mathrm{pH}$ values higher 


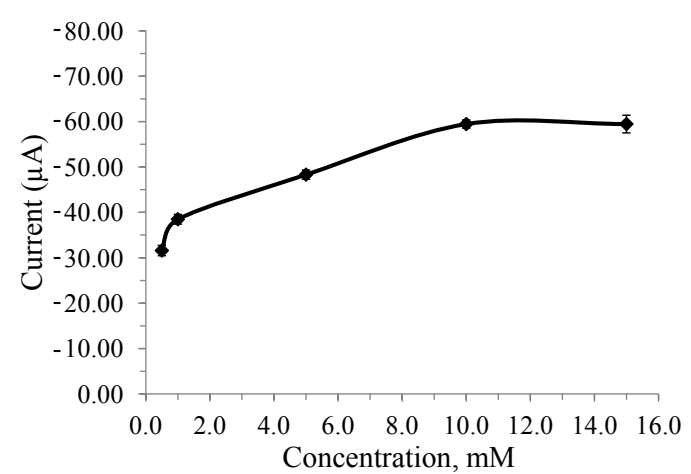

Fig. 6 Peak currents from BDD electrode at concentration of $30.0 \mathrm{mg} / \mathrm{Cd}^{2+}$ in various concentrations of TBAPF 6 $0.5,0.1,5.0,10.0$, and $15.0 \mathrm{mM}(\mathrm{pH} 2$, as an electrolyte for film formation) in acetate buffer solutions $\mathrm{pH} 6.0$ with scan rate of $100 \mathrm{mV} / \mathrm{s}$.

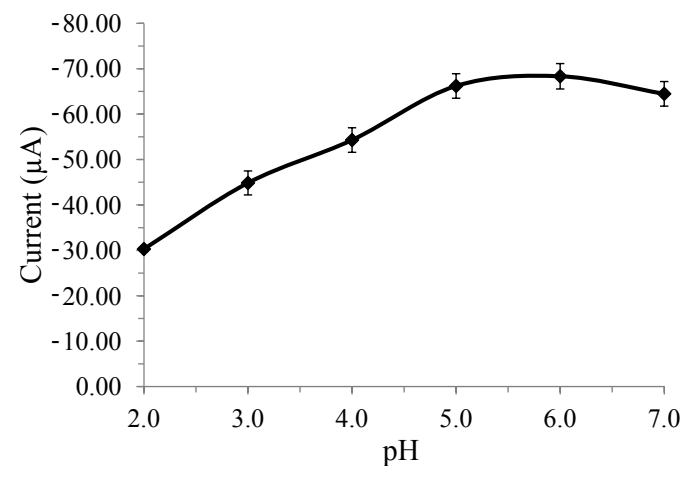

Fig. 7 Peak currents of $30 \mathrm{mg} / 1 \mathrm{Cd}^{2+}$ in acetate buffer at different $\mathrm{pH}$ values.

than 2.0 the peak current decreased drastically possibly due to the formation of insoluble metal hydroxide complex, $\mathrm{Cd}(\mathrm{OH})_{2}$. Thus $\mathrm{pH} 2.0$ was selected as an optimum condition in order to obtain maximum sensitivity in quantitative analytical measurements. The effects of electrolytes concentration at $0.5,1.0$, $5.0,10.0$, and $15.0 \mathrm{nM} \mathrm{TBAPF}_{6}$ on the peak currents of $\mathrm{Cd}^{2+}$ were also carefully investigated. It was found that $\mathrm{Cd}^{2+}$ had the best electrochemical responses in $10 \mathrm{mM} \mathrm{TBAPF}_{6}$ (Fig. 6), which was chosen as a supporting electrolyte for voltammetric determination of the $\mathrm{Cd}^{2+}$ for further experiments.

\section{Effect of $\mathrm{pH}$ on $\mathrm{Cd}^{2+}$ determination}

The effect of $\mathrm{pH} 1.0-7.0$ on the peak current of $\mathrm{Cd}^{2+}$ in SWASV is shown in Fig. 7. The results indicate a rapid enhancement of the peak current of $\mathrm{Cd}^{2+}$ with ascending of $\mathrm{pH}$ to a maximum approximately at $\mathrm{pH} 6.0$ and then a progressive decrease. This

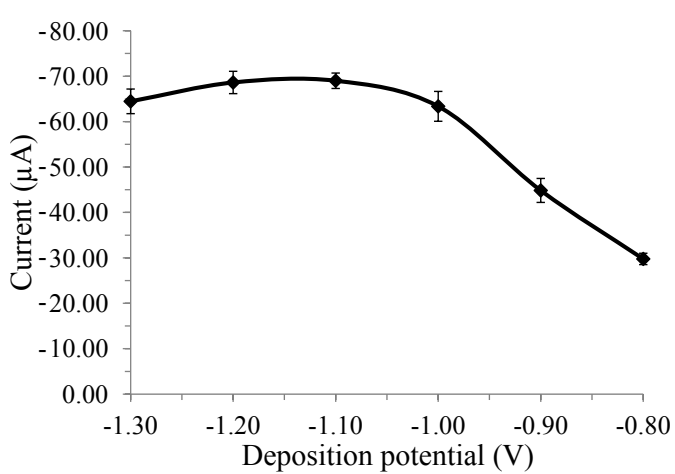

Fig. 8 Effect of deposition potentials on the SWASV peak currents. Conditions: $30.0 \mathrm{mg} / \mathrm{l} \mathrm{Cd}^{2+}$ in $50 \mathrm{ml}$ acetate buffer $\mathrm{pH}$ 6.0.

might result from the higher $\mathrm{pH}$ value, at which the metal ion easily hydrolyses ${ }^{35}$. At lower $\mathrm{pH}$ value, hydrogen ion are reduced more easily ${ }^{36}$, which in turn interfere with $\mathrm{Cd}^{2+}$ deposition. $\mathrm{pH} 6.0$ was therefore chosen for further studies.

\section{Deposition potential}

The effect of deposition potentials on the stripping peak currents of $30.0 \mathrm{mg} / 1 \mathrm{Cd}^{2+}$ was studied in the potential range from -0.80 to $-1.30 \mathrm{~V}$ (Fig. 8). The negative shifts of deposition potential can clearly improve the extent of $\mathrm{Cd}^{2+}$ reduction on the surface electrode and increase the peak current. The peak current however does not change significantly with the deposition potentials to values more negative than $-1.10 \mathrm{~V}$. Moreover, the background current increased when the potentials were more positive than $-1.10 \mathrm{~V}$. The results reflect an optimum deposition potential of $-1.10 \mathrm{~V}$ at which further experiments were then performed to achieve high sensitivity and better response.

\section{Deposition time}

For the effect of the deposition time screened within a range of 1-8 min on the stripping currents of $20.0 \mu \mathrm{g} / 1 \mathrm{Cd}^{2+}$, longer deposition times should increase the peak current because more $\mathrm{Cd}^{2+}$ could be deposited (Fig. 9). When the deposition time increases, the stripping peak currents increase greatly and are almost constant beyond 6 min which reflects surface saturation. Thus 6 min was chosen for all subsequent analysis.

\section{Scan rate}

The scan rate was screened from $10-200 \mathrm{mV} / \mathrm{s}$. As shown in Fig. 10, the peak height was small at lower 


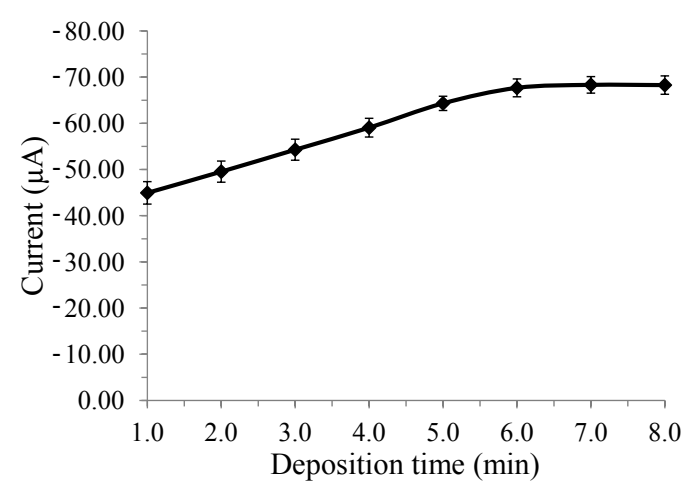

Fig. 9 Effect of deposition time on the SWASV peak currents. Conditions: $30.0 \mathrm{mg} / \mathrm{C} \mathrm{Cd}^{2+}$ in $50 \mathrm{ml}$ acetate buffer pH 6.0.

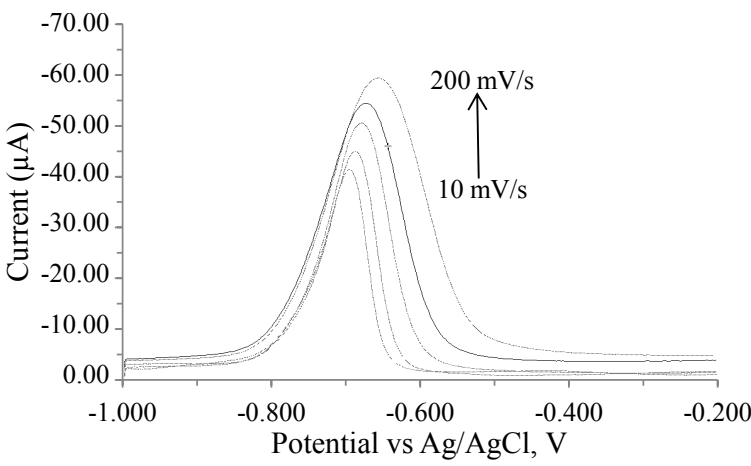

Fig. 10 Effect of scan rates 10, 20, 50, 100, and $200 \mathrm{mV} / \mathrm{s}$ on the stripping voltammograms. Conditions: $30.0 \mathrm{mg} / \mathrm{l} \mathrm{Cd}^{2+}$ in $50 \mathrm{ml}$ acetate buffer $\mathrm{pH} 6.0,0.5 \mathrm{mM}$ 4-aminomethyl benzoic acid; deposition potential, $-1.1 \mathrm{~V}$ versus $\mathrm{Ag} / \mathrm{AgCl}$; deposition time, $6 \mathrm{~min}$; pulse amplitude, $4 \mathrm{mV}$.

scan rate and increased rapidly at higher scan rate with the best result of better current and greater stability of peak potential at a scan rate of $100 \mathrm{mV} / \mathrm{s}$. At more than $200 \mathrm{mV} / \mathrm{s}$, the signal peak becomes broader and shifts to much more positive stripping potentials. A scan rate of $100 \mathrm{mV} / \mathrm{s}$ was therefore selected for further experiments.

\section{Limits of detection and quantitation}

Fig. 11a shows square wave voltammetry measurements of water with different concentrations of $\mathrm{Cd}^{2+}$ with the optimum conditions to obtain the calibration curve and detection limit. The calibration curve shows linearity within the range of $2-50 \mathrm{ppb}$ with a correlation coefficient of 0.9989 with the linear regression equation of $\mathrm{Cd}^{2+}$ of $i_{\mathrm{p}}=4.458 x-11.73$ $\left(i_{\mathrm{p}}: \mu \mathrm{A}, x: \mu \mathrm{g} / 1\right)$.
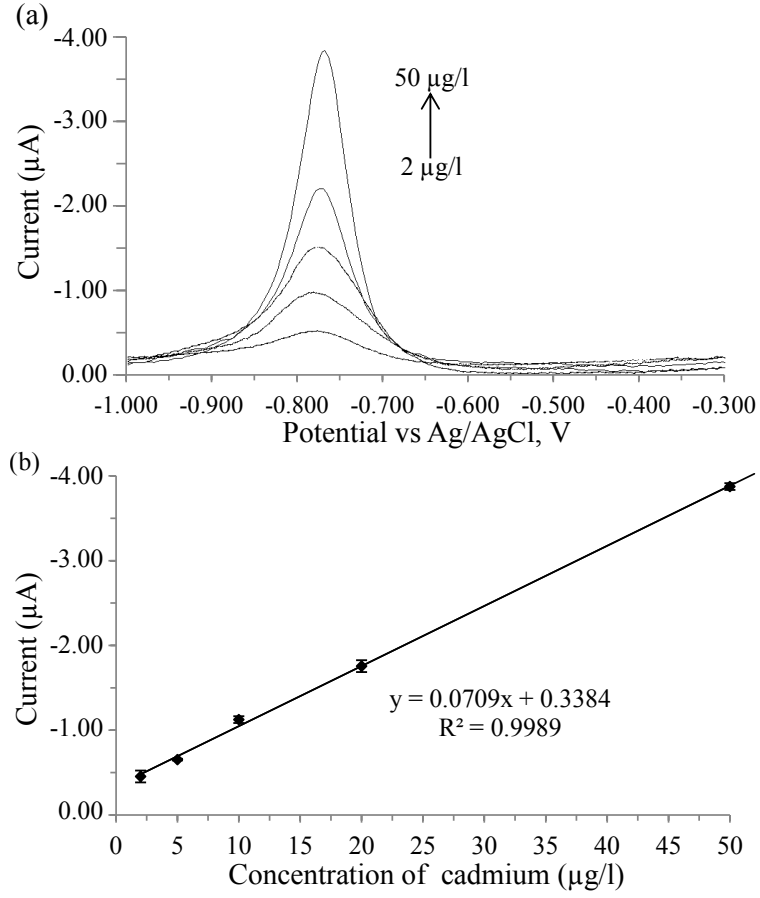

Fig. 11 SWAS voltammograms of water sample. After spiking with 2.0, 5.0, 10.0, 20.0, and $50.0 \mu \mathrm{g} / 1$ of $\mathrm{Cd}^{2+}$ standard solution. Conditions; accumulation potential, $-1.10 \mathrm{~V}$; accumulation time, $6 \mathrm{~min}$; acetate buffer pH 6.0, $0.5 \mathrm{mM}$ 4-aminomethyl benzoic acid; scan rate, $100 \mathrm{mV} / \mathrm{s}$.

The limit of detection of $\mathrm{Cd}^{2+}$ was calculated by $\mathrm{LOD}=3 \mathrm{~N} / \mathrm{m}^{36}$, where $N$ is the standard deviation of replicate blank responses $(n=9)$ and $m$ is the slope of the calibration curve to obtain its value of $0.2 \mu \mathrm{g} / \mathrm{l}$. The limits of quantification defined as $10 \mathrm{~N} / \mathrm{m}$, were found to be $0.6 \mu \mathrm{g} / \mathrm{l}$. The relative standard deviation was $3 \%(n=10)$ for repetitive determinations of $20.0 \mu \mathrm{g} / 1$ of $\mathrm{Cd}^{2+}$. The results demonstrate that the proposed technique was reproducible and reliable for the detection of $\mathrm{Cd}^{2+}$ at trace level and can be used for real samples analysis.

\section{Certified reference materials and real sample analysis}

The accuracy of the proposed method was tested by determining the $\mathrm{Cd}^{2+}$ content of certified reference materials, natural water SRM 1640 from NIST. Stripping peaks for $\mathrm{Cd}^{2+}$ in the NIST sample occur at potentials of $-0.72 \mathrm{~V}$ versus $\mathrm{AgCl}$. The certified value $(22.82 \pm 0.96 \mu \mathrm{g} / \mathrm{l})$ and the analytical results $(22.72 \pm 0.90 \mu \mathrm{g} / 1, n=5)$ gave a satisfactory recovery of $99.02 \%(n=5)$, proving that the proposed method is suitable for analysing tap water sample. 
Table 1 Determination of $\mathrm{Cd}^{2+}$ in tap water samples $(n=4)$ spiked with 5,10 , and $20 \mu \mathrm{g} / 1$ of $\mathrm{Cd}^{2+}$.

\begin{tabular}{|c|c|c|c|c|c|}
\hline Sample & Spiked $(\mu g / 1)$ & Present method $(\mu \mathrm{g} / \mathrm{l})^{\mathrm{b}}$ & Recovery (\%) & ICP-OES method $(\mu \mathrm{g} / 1)$ & Difference (\%) \\
\hline \multirow[t]{4}{*}{ Tap water $1^{\mathrm{a}}$} & 0 & $\mathrm{ND}^{\mathrm{c}}$ & - & ND & - \\
\hline & 5 & $5.56 \pm 0.35$ & - & $5.25 \pm 0.65$ & 6.2 \\
\hline & 10 & $10.65 \pm 0.52$ & 101.8 & $10.35 \pm 0.45$ & 3.0 \\
\hline & 20 & $20.35 \pm 0.24$ & 97.0 & $20.78 \pm 0.32$ & 2.2 \\
\hline \multirow[t]{4}{*}{ Tap water $2^{\mathrm{a}}$} & 0 & ND & - & ND & - \\
\hline & 5 & $5.28 \pm 0.25$ & - & $5.58 \pm 0.48$ & 6.0 \\
\hline & 10 & $10.35 \pm 0.58$ & 101.4 & $10.14 \pm 0.65$ & 2.1 \\
\hline & 20 & $20.20 \pm 0.68$ & 98.5 & $20.25 \pm 0.56$ & 0.2 \\
\hline
\end{tabular}

${ }^{\text {a }}$ Water sample 1st and 2nd region was selected for standard addition test

${ }^{\mathrm{b}}$ Mean \pm Standard deviation $(n=4)$

${ }^{\text {c }}$ Not detected

Table 2 Comparison of the proposed method to determine $\mathrm{Cd}^{2+}$ in water sample with other anodic stripping voltammetric methods.

\begin{tabular}{|c|c|c|c|c|c|}
\hline Modified electrode & Method & Deposition time (s) & Linear range $(\mu \mathrm{g} / \mathrm{l})$ & Detection limit $(\mu \mathrm{g} / \mathrm{l})$ & Reference \\
\hline (Bi/MCNTs-CPE) & SWASV & 7200 & $1-60$ & 0.3 & Ref. 37 \\
\hline Sb nano/BDD & LSASV & 120 & $50-500$ & 38.10 & Ref. 38 \\
\hline $\mathrm{Bi} / \mathrm{CNT} / \mathrm{GCE}$ & SWASV & 300 & $2-100$ & 0.70 & Ref. 39 \\
\hline $0.2 \mathrm{M}$ 4-aminomethyl benzoic acid/BDD & SWASV & 360 & $2-50$ & 0.2 & This work \\
\hline
\end{tabular}

The proposed technique was applied to the analysis of $\mathrm{Cd}^{2+}$ in tap water sample collected from 11 sites in Hatyai city, $500 \mathrm{ml}$ for each. The standard addition method was performed by spiking a tap water sample with different concentrations of $\mathrm{Cd}^{2+}$ with the results in Table 1 . The recoveries values were between 97 and 102\%. The results obtained by the proposed method were compared with those obtained by the inductively coupled plasma optical emission spectrometry (ICP-OES). Statistical analysis of the results by the Student's $t$-test and variance ratio $F$-test (Table 1) revealed that factors calculated did not exceed the theoretical value $(95 \%$ confidence limits for three degrees of freedom) or there was no significant difference between the proposed methods and the standard method. Thus the technique provides a good alternative for the determination of $\mathrm{Cd}^{2+}$ in tap water sample. Compared with other ASV techniques using modified electrodes, the proposed method exhibits better figures of merit (Table 2), revealing that this technique is among those with the highest sensitivity.

\section{Effect of other ions}

To study the selectivity of the proposed method, some metal ions were tested to evaluate the possible interference with the detection of $\mathrm{Cd}^{2+}$. The ions were considered to interfere seriously when they gave a current signal change of more than $5 \%$. The experimental results for typical ions present
Table 3 Potential ion interference on the voltammetric response of $20.0 \mu \mathrm{g} / \mathrm{C} \mathrm{Cd}^{2+}$ under optimum conditions.

\begin{tabular}{lcc}
\hline Foreign ions & Concentration $(\mu \mathrm{g} / \mathrm{l})$ & Signal change (\%) \\
\hline $\mathrm{Ca}^{2+}$ & 2600 & -5.56 \\
$\mathrm{Mg}^{2+}$ & 1000 & -5.35 \\
$\mathrm{Zn}^{2+}$ & 1000 & -5.89 \\
$\mathrm{Mn}^{2+}$ & 400 & -5.36 \\
$\mathrm{Fe}^{2+}$ & 200 & -5.56 \\
$\mathrm{Cu}^{2+}$ & 200 & -5.98 \\
$\mathrm{Al}^{3+}$ & 80 & -5.89 \\
$\mathrm{Co}^{2+}$ & 40 & -5.78 \\
$\mathrm{~Pb}^{2+}$ & 40 & -5.96 \\
$\mathrm{Ni}^{2+}$ & 20 & -5.75 \\
\hline
\end{tabular}

in tap water samples are given in Table 3. The peak current of $\mathrm{Cd}^{2+}$ was not significantly affected by substantial excess of $\mathrm{Ca}^{2+}, \mathrm{Mg}^{2+}, \mathrm{Zn}^{2+}, \mathrm{Mn}^{2+}$, $\mathrm{Fe}^{2+}, \mathrm{Cu}^{2+}$, and $\mathrm{Al}^{3+}$. However, $\mathrm{Co}^{2+}, \mathrm{Pb}^{2+}$, and $\mathrm{Ni}^{2+}$ significantly influenced the stripping response. These ions not only compete with $\mathrm{Cd}^{2+}$ for the substitution on the surface electrode but can also form intermetallic compounds with $\mathrm{Cd}^{2+}$ to prevent its accumulation on the electrode ${ }^{13}$. However, the influence of weakly interfering ions can be corrected by standard addition method. Thus the results demonstrate sufficient selectivity of the proposed method. 


\section{CONCLUSIONS}

A simple and accurate method was developed for the analysis of trace $\mathrm{Cd}^{2+}$ in drinking water using the BDD electrode in combination with SWASV. The electrode exhibited a single stripping anodic signal at $-0.72 \mathrm{~V}$, of which the intensity increased linearly with $\mathrm{Cd}^{2+}$ concentration range of $2-50 \mu \mathrm{g} / \mathrm{l}$. The detection limit achieved with $0.2 \mathrm{M}$ 4-aminomethyl benzoic acid-modified BDD electrode for $\mathrm{Cd}^{2+}$ was $0.2 \mathrm{ppb}$. Good repeatability (recoveries between 96 and $102 \%, n=4$ ) and reproducibility (recovery of $99.02 \%, n=5$ ) in the measurements were also obtained. The method was applied with tap water samples to reveal better sensitivity, simpler sample preparation, shorter analysis time and easier operational processing. The accuracy of the proposed method was verified by analysing the SRM 1640 natural water standard with the certified value of $22.82 \pm 0.96 \mu \mathrm{g} / 1$ yielded $\mathrm{Cd}^{2+}$ concentration of $22.72 \pm 0.90 \mu \mathrm{g} / \mathrm{l}(n=3)$. The recoveries of the method by spiking were in the range of $85-105 \%$. The results of $\mathrm{Cd}^{2+}$ in natural water samples analysed by the developed method (FI-DPASV) were in good agreement with those obtained by Inductively Coupled Plasma-Optical Emission Spectrometry. The concentration of $\mathrm{Cd}^{2+}$ in tap water samples were found to be lower than the drinking water contamination standard limited level $3.0 \mu \mathrm{g} / 1$ issued by the World Health Organization and Provincial Waterworks Authority of Thailand.

\section{REFERENCES}

1. Li Y, Liu X, Zeng X, Liu Y, Liu X, Wei W, Luo S (2009) Simultaneous determination of ultra-trace lead and cadmium at a hydroxyapatite-modified carbon ionic liquid electrode by square-wave stripping voltammetry. Sensor Actuator B 139, 604-10.

2. McGaw EA, Swain GM (2006) A comparison of boron-doped diamond thin-film and $\mathrm{Hg}$-coated glassy carbon electrodes for anodic stripping voltammetric determination of heavy metal ions in aqueous media. Anal Chim Acta 575, 180-9.

3. Järup L, Berglund M, Elinder CG, Nordberg G, Vahter M (1998) Health effects of cadmium exposure-a review of the literature and a risk estimate. Scand $J$ Work Environ Health 24, Suppl 1, 1-51.

4. Thomas S, Mohaideen JA (2014) Determination of cadmium in water, sediment and spotted seer fish. Int $J$ Latest Trends Eng Tech 3, 280-4.

5. Syers JK, Mackay AD, Brown MW, Currie CD (1986) Chemical and physical characteristics of phosphate rock materials of varying reactivity. J Sci Food Agr 37, 1057-64.

6. Trueman NA (1965) The phosphate, volcanic and carbonate rocks of Christmas Island (Indian Ocean). J Geol Soc Aust 12, 261-83.

7. Taylor MD (1997) Accumulation of cadmium derived from fertilisers in New Zealand soils. Sci Total Environ 208, 123-6.

8. www.kanazawa-med.ac.jp/ pubhealt/cadmium2/ itaiitai-e/itai01.html

9. Al-Shawi AW, Dahl R (1996) Determination of lanthanides in magnesium alloys by ion chromatography. Anal Chim Acta 333, 23-30.

10. Lau OW, Ho SY (1993) Simultaneous determination of traces of iron, cobalt, nickel, copper, mercury and lead in water by energy-dispersive X-ray fluorescence spectrometry after preconcentration as their piperazino-1, 4-bis(dithiocarbamate) complexes. Anal Chim Acta 280, 269-77.

11. Liu RM, Liu DJ, Sun AL (1993) Simultaneous determination of multicomponents by flow injection analysis. Talanta 40, 511-4.

12. Langeloth M, Chiku M, Einaga Y (2010) Anodic stripping voltammetry of zinc at boron-doped diamond electrodes in ammonia buffer solution. Electrochim Acta 55, 2824-8.

13. Yi WJ, Li Y, Ran G, Luo HQ, Li NB (2012) Determination of cadmium(II) by square wave anodic stripping voltammetry using bismuth-antimony film electrode. Sensor Actuator B 166, 544-8.

14. Wang J, Lu J, Hocevar SB, Farias PAM (2000) Bismuth-coated carbon electrodes for anodic stripping voltammetry. Anal Chem 72, 3218-22.

15. Wang J, Tian B (1993) Mercury-free disposable lead sensors based on potentiometric stripping analysis at gold-coated screen-printed electrodes. Anal Chem 65, 1529-32.

16. Zhang XH, Wang SF (2005) Determination of ethamsylate in the presence of catecholamines using 4amino-2-mercaptopyrimidine self-assembled monolayer gold electrode. Sensor Actuator B 104, 29-34.

17. Brand M, Eshkenazi I, Kirowa-Eisner E (1997) The silver electrode in square wave anodic stripping voltammetry: determination of $\mathrm{Pb}^{2+}$ without removal of oxygen. Anal Chem 69, 4660-4.

18. Krasnodebska-Ostrega B, Piekarska J (2005) Determination of lead and cadmium at silver electrode by subtractive anodic stripping voltammetry in plant materials containing Tl. Electroanalysis 17, 815-8.

19. Di J, Zhang F (2003) Voltammetry determination of trace manganese with pretreatment glassy carbon electrode by linear sweep voltammetry. Talanta $\mathbf{6 0}$, 31-6.

20. Calvo-Marzal P, Chumbimuni-Torrs KY, Höehr NF, Neto GO, Kubota LT (2004) Determination of reduced glutathione using an amperometric carbon paste electrode chemically modified with TTF-TCNQ. Sensor Actuator B 100, 333-40.

21. Roa-Morales G, Ramírez-Silva MT, López González R, Galicia L, Romero-Romo M (2005) Electrochemical 
characterization and determination of mercury using carbon paste electrodes modified with cyclodextrins. Electroanalysis 17, 694-700.

22. Hu C, Wu K, Dai X, Hu S (2003) Simultaneous determination of lead(II) and cadmium(II) at a diacetyldioxime modified carbon paste electrode by differential pulse stripping voltammetry. Talanta 60 , 17-24.

23. He JB, Chen CL, Liu JH (2004) Study of multi-wall carbon nanotubes selfassembled electrode and its application to the determination of carbon monoxide. Sensor Actuator B 99, 1-5.

24. Honeychurch KC, Hart JP, Cowell DC, Arrigan DW (2002) Voltammetric behavior and trace determination of cadmium at a calixarene modified screenprinted carbon electrode. Electroanalysis 14, 177-85.

25. Fierro S, Watanabe T, Akai K, Einagaa Y (2012) Highly sensitive detection of $\mathrm{Cr}^{6+}$ on boron doped diamond electrodes. Electrochim Acta 82, 9-11.

26. Saterlay AJ, Foord JS, Compton RG (1999) Sonocathodic stripping voltammetry of manganese at a polished boron-doped diamond electrode: application to the determination of manganese in instant tea. Analyst 124, 1791-6.

27. Chooto P, Wararatananurak P, Innuphat C (2010) Determination of trace levels of $\mathrm{Pb}$ (II) in tap water by anodic stripping voltammetry with boron-doped diamond electrode. Sci Asia 36, 150-6.

28. Compton RG, Coles BA, Holt K, Foord JS, Markenk F, Tsai YC (2001) Microwave-enhanced anodic stripping detection of lead in a river sediment sample. A mercury-free procedure employing a boron-doped diamond electrode. Electroanalysis 13, 831-5.

29. Saterlay AJ, Marken F, Foord JS, Compton RG (2000) Sonoelectrochemical investigation of silver analysis at a highly boron-doped diamond electrode. Talanta 53, 403-15.

30. Prado C, Wilkins SJ, Marken F, Compton RG (2002) Simultaneous electrochemical detection and determination of lead and copper at boron-doped diamond film electrodes. Electroanalysis 14, 262-72.

31. Fan L, Chen J, Zhu S, Wang M, Xu G (2009) Determination of $\mathrm{Cd}^{2+}$ and $\mathrm{Pb}^{2+}$ on glassy carbon electrode modified by electrochemical reduction of aromatic diazonium salts. Electrochem Comm 11, 1823-5.

32. Picot $M$, Lapinsonnière $L$, Rothballer $M$, Barrière $F$ (2011) Graphite anode surface modification with controlled reduction of specific aryl diazonium salts for improved microbial fuel cells power output. Biosens Bioelectron 28, 181-8.

33. Mooste M, Kibena E, Kozlova J, Marandi M, Matisen L, Niilisk A, Sammelselg V, Tammeveski K (2015) Electrografting and morphological studies of chemical vapour deposition grown graphene sheets modified by electroreduction of aryldiazonium salts. Electrochim Acta 161, 195-204.

34. Bravo I, García-Mendiola T, Revenga-Parra M, Pari- ente F, Lorenzo E (2015) Diazonium salt click chemistry based multiwall carbon nanotube electrocatalytic platforms. Sensor Actuator B 211, 559-68.

35. March G, Nguyen TD, Piro B (2015) Modified electrodes used for electrochemical detection of metal ions in environmental analysis. Biosensors 5, 241-75.

36. Lima FD, Gozzi F, Fiorucci AR, Cardoso CAL, Arruda GJ, Ferreira VS (2011) Determination of linuron in water and vegetable samples using stripping voltammetry with a carbon paste electrode. Talanta 83, 1763-8.

37. Luo JH, Jiao XX, Li NB, Luo HQ (2013) Sensitive determination of Cd(II) by square wave anodic stripping voltammetry with in situ bismuth-modified multiwalled carbon nanotubes doped carbon paste electrodes. J Electroanal Chem 689, 130-4.

38. Toghill KE, Xiao L, Wildgoose GG, Compton RG (2009) Electroanalytical determination of cadmium (II) and lead(II) using an antimony nanoparticle modified boron-doped diamond electrode. Electroanalysis 21, 1113-8.

39. Wang GH, Han WK, Park JS, Kang SG (2008) Determination of trace metals by anodic stripping voltammetry using a bismuth-modified carbon nanotube electrode. Talanta 76, 301-8. 